\title{
Associations between influence of infant feeding patterns on the deciduous second molar relationship in preschool-aged children
}

\author{
Hilda Fitria Lubis*, Sasha Allayya Tiffany** \\ *Faculty of Dentistry, Universitas Sumatera Utara, North Sumatra, Indonesia \\ **Department of Orthodontics, Universitas Sumatera Utara, North Sumatra, Indonesia \\ *Jl Alumni No 2, Kampus Medan, North Sumatra, Indonesia; e-mail: hildadrgusu @gmail.com
}

Submitted: $2^{\text {nd }}$ November 2018; Revised: $18^{\text {th }}$ March 2019; Accepted: $2^{\text {nd }}$ April 2019

\begin{abstract}
Exclusive breastfeeding during the first six months of life is extremely important for the development of the dentocraniofacial structure, occlusion, breathing and swallowing during childhood. The prevalence severity rate of malocclusion in children who were breastfed is lower than those who were bottle-fed. The aim of this study is to evaluate the associations of infant feeding patterns on the deciduous second molar relationship in preschool aged children (3-5 years old children) of selected preschools in and around Medan Selayang. This study used analytic cross-sectional study design as the research method. The sampling was carried out by purposive sampling technique. This study involved 130 children aged 3-5 years as the sample, who consisted of two groups, the exclusively breastfed group and the bottle-fed group with the inclusion criteria of the children having a good oral and dental health. The result is statistically analyzed using Chi Square with a significance level of $p<0.05$. There was a significant difference between children who were breastfed and those who were bottle-fed. Children who were breastfed mostly had mesial step (55, $4 \%$ ), followed by distal step $(27.7 \%)$ and flush (16.9\%), while those children who were bottle-fed mostly had distal step (46.2\%), flush (33.8\%), and mesial steps $(20 \%)$. Based on Chi Square test, it is shown that there is a significant relationship between infant feeding patterns to primary molar relationships $(p<0.001)$.
\end{abstract}

Keywords: breastfeeding; bottle-feeding; primary molar relationship

\section{INTRODUCTION}

Mother's milk contains nutritional content to strengthen the immune system to prevent diseases. Breastfeeding for children usually starts from birth until they reach the age of two. ${ }^{1,2}$ According to World Breastfeeding Trends Initiative in 2012, only $46.8 \%$ of women who exclusively breastfed their infants for up to six months and $12.5 \%$ women bottle-fed their infants. ${ }^{1,3}$ In Indonesia, the percentage of exclusive breastfeeding based on RISKESDAS in 2013 was only $54.3 \%$, with the highest percentage in West Nusa Tenggara with $79.7 \%$ and the lowest in Maluku Province at about $25.2 \%{ }^{4}$

Pediatrician and pediatric dentist agreed on the importance of exclusive breastfeeding during the first six months of life for a good development of dentocranifacial structure, occlusion, breathing and swallowing during childhood. American Academy of Pediatric Dentistry considers breast milk an ideal source of nutrition as it provides innumerable health-related advantages. In addition to having a lot of nutrition, breastfeeding is one of the factors in the development of facial structures and has an impact on the health of the baby. Valle et al studied 540 children who were exclusively breastfed during the duration of 6-72 months. The study proved that exclusive breastfeeding will have a good effect on the development of the mandibula. ${ }^{5}$ Children who experienced pure breastfeeding for more than 6 months had a lower chance of developing a class II incisal relationship or an increased overjet, and had wider intercanine and intermolar widths. ${ }^{6}$ Nutritive sucking, which includes breast-feeding and bottlefeeding and non-nutritive sucking (NNS), which includes pacifier and digit sucking, have been associated with growth and development of the maxillomandibular complex. ${ }^{7}$ 
Primasari et al revealed that breastfeeding through the nipple can stimulate the development of dentocraniofacial and it is a major factor in achieving a normal occlusion. An infant who did not get exclusive breastfeeding is going to have a malocclusion. $^{8}$

The prevalence severity rate of malocclusion in children who are breastfed through their mother's nipples is lower than children who were bottle-fed. ${ }^{9}$ Several studies have discussed the relationship between breastfeeding and bottle-feeding on the primary molar relationship. According to Dutra et al, it is very important to know the variation in the terminal relationship of primary second molars and their effect on the occlusal pathway of permanent tooth growth to prevent malocclusion. ${ }^{9}$ Sargod et al stated that determining the primary molar relationship from an early age is an important step to predict the relationship of the permanent molar in the future. ${ }^{1}$ For example, mesial step can be predicted as class I and the distal step can be predicted as class II Angle. . $^{3,9,10}$

Sargod et al. who studied 100 children revealed that $45 \%$ were exclusively breastfed, $18 \%$ were exclusively bottle-fed, and $37 \%$ were bottle-fed in addition to breastfeeding. In children, who were exclusively breastfed, 37 (84.09\%) had a mesial step occlusion, 4 (9.09\%) had a distal step occlusion, and $4(9.09 \%)$ had a flush terminal plane occlusion. Meanwhile, of those children who were exclusively bottle-fed, only $4(22.2 \%)$ had a mesial step occlusion, while $9(50 \%)$ had a distal step occlusion, and $5(27.7 \%)$ showed a flush terminal plane occlusion. In the children who had a combination feeding, i.e., complementary bottlefeeding along with breastfeeding, 29 (78.37\%) showed a mesial step occlusion, $4(10.8 \%)$ had a distal step occlusion, and 4 (10.8\%) showed a flush terminal plane occlusion. ${ }^{1}$

Babu et al. stated that milk consumption patterns affected the occlusion and showed a significant difference between breastfeeding for 1-2 years that leads to a mesial step and bottle- feeding for 1-2 years that often leads to a distal step. ${ }^{11}$ Considering the importance of primary second molar relationship as a determinant of permanent molar relationship in the future, it is necessary to know the factors that influence the primary molar relationship. There are only a few researches to address the issue, especially in Medan areas. Therefore, this study aims to evaluate the associations between infant feeding patterns on the deciduous second molar relationship of preschool aged children.

\section{MATERIALS AND METHODS}

This research is an analytic study with crosssectional design approach. The population are the children aged 3-5 years old and their mothers in Medan Selayang area. The non probability sampling with purposive technique is applied to collect 130 samples in selected preschools. The chosen schools were Khansa, Galilea Hosana, and Fadhil Al Insani. In this study, samples were divided into two groups that consist of exclusively breastfed and bottle-fed groups.

The inclusion criterias were parents and their children that do not have systemic disease and the child who has complete deciduous teeth and absence of proximal caries. The exclusion criterias were the children with malformed teeth, cleft palate, cleft lip, craniofacial deformation and had history of speech therapy.

This study received ethical clearance from Health Research Ethical Committee Faculty of Medicine, Universitas Sumatera Utara (NO:502/ TGL/KEPK FK USU-RSUP HAM/ 2018) and parents had to sign an informed consent to proceed the research. The parents were given questionnaries of feeding patterns and the duration of feeding. Caries and relationship of primary second molar examination were held to determine the criteria. Furthermore, the relationship of primary second molar were captured by a camera (Nikon D90., Nikon Corporation, Japan) for data records. Data processing was analyzed by computer analysis using Chi Square with $95 \%$ of significance level.

\section{RESULTS}

Of the 130 sample respondents aged 3-5 years, $55.4 \%$ are male and $44.6 \%$ are female. The highest number of respondents are those aged 5 years old 
by $50.8 \%$, followed by the 4 years old with $27.7 \%$ and $21.5 \%$ of those aged 3 years old (Table 1 ).

Based on milk consumption and duration of milk feeding, it was found that children who were breastfed or bottle-fed had the same percentage $(50 \%)$. In terms of milk feeding time span, the children who consumed milk for 1-2 years constituted as the highest number with $63.8 \%$, followed by those consuming milk for more than $>$ 2 years at $24.6 \%$, and the smallest number were found for those consuming milk for only 6 month - 1 year at $11.5 \%$. Children who had milk feeding frequency of more than $>5$ times a day constituted as the highest percentage with $78.5 \%$, while those having 3-5 times of milk feeding a day was $21.5 \%$. Most children spent the time for each milk feeding for about $10-15$ minute (43.1\%), followed by those spending time for milk feeding for about 20-30 minutes $(33.8 \%)$ and the least number of children spent time for milk feeding for more than 30 minutes $(23.1 \%)$ (Table 2). The examination of the primary molar relationship, $37.7 \%$ of respondents had a mesial step, $36.9 \%$ a distal step and $25.4 \%$ had a flush (Table 3).

The primary molar relationship to the length of bottle-feeding revealed that the children who received bottle-feeding for 6 months- 1 year had the highest rate of flush (5 samples), followed by distal step (4 samples), and mesial step (1 sample). On the other hand, children who were bottle-fed for more than $>1-2$ years mostly had a distal step (17 samples), followed by a flush (11 samples), and a mesial step (9 samples), while children who were bottle-fed for more than $>2$ years had a flush (9 samples), a distal step (9 samples), and none had mesial steps (Table 4).

Children who were breastfed for 6 months-1 year mostly had a mesial step (2 samples), a flush (2 samples), and a distal step (1 sample). Children who were breastfed for more than $>1$ year- 2 years mostly had a mesial step (34 samples), followed by a distal step (11 samples), and a flush as the least (1 sample). Children who were breastfed for more than $>2$ years mostly had distal step (6 samples) (Table 5).
The associations between infant feeding pattern and primary molars relationship reveals that the child who were breastfed mostly had a mesial step $(55.4 \%)$, while the child who were bottle-fed mostly had a distal step (46.2\%). The results of the statistical analysis showed a significant relationship between the infant feeding pattern and the primary molar relationship $(p<0.0001)$ (Table 6).

Table 1. Distribution of respondents' characteristics in preschool in Medan $(n=130)$

\begin{tabular}{lcc}
\hline \multicolumn{1}{c}{ Characteristics } & Amount & Percentage (\%) \\
\hline Gender & & \\
Male & 72 & 55.4 \\
Female & 58 & 44.6 \\
\hline Age & & \\
3 years & 28 & 21.5 \\
4 years & 36 & 27.7 \\
5 years & 66 & 50.8 \\
\hline
\end{tabular}

Table 2. Distribution of milk consumption patterns in children ( $\mathrm{n}$ =130)

\begin{tabular}{lcc}
\hline Milk consumption pattern & Amount & Percentage (\%) \\
\hline Feeding method & & 50 \\
Breastfeeding & 65 & 50 \\
Bottlefeeding & 65 & \\
\hline Length of feeding & & 11.5 \\
6 months - 1 year & 15 & 63.8 \\
12 years old & 83 & 24.6 \\
$>2$ years & 32 & \\
\hline Feeding frequency & & 21.5 \\
$3-5$ times & 28 & 78.5 \\
$>5$ times & 102 & \\
\hline Feeding duration & & 43.1 \\
$10-15$ minutes & 56 & 33.8 \\
$20-30$ minutes & 44 & 23.1 \\
$>30$ minutes & 30 & \\
\hline
\end{tabular}

Table 3. Distribution of primary molar relations

\begin{tabular}{lcc}
\hline \multicolumn{1}{c}{ Characteristics } & Amount & Percentage (\%) \\
\hline Distal step & 48 & 36.9 \\
Mesial step & 49 & 37.7 \\
Flush & 33 & 25.4 \\
\hline
\end{tabular}

Table 4. The primary molar relationship with the length of bottlefeedinging

\begin{tabular}{lccc}
\hline \multicolumn{1}{c}{ Prolonged feeding } & $\begin{array}{c}\text { Mesial } \\
\text { step }\end{array}$ & $\begin{array}{c}\text { Distal } \\
\text { step }\end{array}$ & flush \\
\hline 6 months - 1 year & 1 & 4 & 5 \\
$>$ 1-2 years & 9 & 17 & 11 \\
$>$ 2 years & 0 & 9 & 9 \\
\hline
\end{tabular}


Majalah Kedokteran Gigi Indonesia. April 2019; 5(1): 23 - 28

ISSN 2460-0164 (print)

ISSN 2442-2576 (online)

Table 5. The primary molar relationship with the length of breastfeeding

\begin{tabular}{lcccc}
\hline \multicolumn{1}{c}{ Prolonged feeding } & $\begin{array}{c}\text { Mesial } \\
\text { step }\end{array}$ & $\begin{array}{c}\text { Distal } \\
\text { step }\end{array}$ & Flush \\
\hline 6 months -1 year & 2 & 1 & 2 \\
$>1$-2 years & 34 & 11 & 1 \\
$>$ 2 years & 3 & 6 & 5 \\
\hline
\end{tabular}

\section{DISCUSSION}

Pediatricians and pediatric dentists agree on the importance of exclusive breastfeeding during the first six months of birth for good development of the structure of the oral cavity, occlusion, breathing and swallowing functions during childhood. ${ }^{1,4}$ Distribution of milk consumption patterns in children result showed that there are $63.8 \%$ mother who fed their children for 1-2 years. This result exceeded Indonesian Ministry of Health Data and Information Survey Center that stated there are $42 \%$ mother who exclusively breastfed their infants for 6 months of life and $29 \%$ others bottle-fed them. This happened due to the high level of public awareness for exclusive breastfeeding and the high flow of mother's milk that eases milk feeding. ${ }^{4}$

The distribution of relationship of primary second molar indicated that there were 49 children who had a mesial step, 48 had a distal step, and 33 others had a flush. Relationship of deciduous teeth in children that were bottle-fed for more than 1-2 years indicated there were 17 children had a distal step, 11 had a flush, and 9 had a mesial step. Furthermore, the results of primary second molar relationship in children highlighted that breastfeeding for more than 1-2 years showed that 37 children had a mesial step, 11 had a distal step and 2 others had a flush. This research confirms Babu et al. research stating that milk consumption patterns affect the occlusion and showed a significant difference between breastfeeding for 1-2 years that leads to a mesial step and bottlefeedinging for 1-2 years that often leads to a distal step. ${ }^{11}$ Romero stated that breastfeeding promotes adequate development of the oral myofunctional structures. Although shorter breastfeeding practices play an indirect role in the etiology of malocclusions, the extent to breastfeeding duration also plays a significant role. ${ }^{12}$ Nahás-Scocate stated that the longer the breastfeeding duration, the higher the percentage of children who did not have the bottle-feedinging habit, and the longer the time span for breastfeeding, the lower the chances of presenting distal step. ${ }^{13}$ Children who were not breastfed or who were breastfed for less than 3 months presented 3 or 4 times greater chances, respectively, of developing distal steps in comparison with the children who were breastfed for more than 12 months. ${ }^{13,14}$

There are relations between breastfeeding and bottle-feedinging on primary second molar relationship. The results showed that $55.4 \%$ children who were breastfed tend to had a mesial step and $46.2 \%$ children had a distal step. This result confirms Sargod et al research which showed that there were $84 \%$ breastfed children who had a mesial step and $50 \%$ bottlefed children who had a distal step. Infant feeding patterns affect growth and development in children, since by the age of three, primary molar relationship will be formed and act as the key of occlusions in permanent teeth. Mesial step considers to develop as a class I and distal step develops to class II. ${ }^{1}$

There are significant relationship between breastfeeding and bottle-feedinging in primary molar relationship because the physicological nipple flows milk continuously from its pores as the child sucks. When the child sucked the nipple, babies need more energy and the use of sternus muscles will stimulate the mandibular growth properly. The contractive forces on sternus muscles supply additional effect to the growth of mandibular. The flexible and soft texture of mother's nipple is beneficial in shaping the hard palate which is caused by the forces made by muscles and mother's nipple that flattens and broadens the palate. As the infant uses a peristaltic-like motion to obtain milk from mother's nipple, the hard palate is shaped by the infants' tongue to develope a U-shaped palatum physiologically. This shape will align teeth properly and reduce the incidence of malocclusions. ${ }^{1,5,15}$

Bottlefed children do not need as much energy as breastfeeding because the entire structure of the rubber surface of the milk bottle pacifier has approached the mother's nipple structure and uses 
more rigid material. ${ }^{12}$ The movement of tongue resembles a piston-like movement in the bottlefed child. Children usually acquired a minimal movement in bottle-feedinging than breastfeeding. Piston-like movement to obtain milk from bottle needs less muscle forces than breastfeeding. This results confirm Ria et al. research that breastfeeding stimulates dentocraniofacial growth better and can affect dental arch and palatal shape to acquire a normal occlusion. The effects of dentofacial development depend on the duration and frequency of feeding, the intensity of milk sucking, arch relations, and the energy produced naturally by the oral cavity muscles. ${ }^{16}$ Sargod et al. said that risk factors to lead to malocclusion are five times greater in children who were bottle-fed. This is so because the use of cheek and tongue muscles in babies with bottle-fed is higher, but the level of efficiency is lower than that of exclusive breastfeeding. ${ }^{1}$ This different suction mechanism causes babies who are bottle-fed more likely to experience crowded malocclusion. ${ }^{17}$ Therefore, the children who were breastfed tend to have more mesial steps than the bottle-fed, who are predicted to develop in class I occlusions. $1,5,11$

\section{REFERENCES}

1. Sargod SS, Bhat SS, Abdul RS. Influence of infant feeding patterns on the deciduous second molar relationship. Arch Med Health Sci. 2016; 4: 9-12.

doi: 10.4103/2321-4848.183348

2. UNICEF. Economic and social statistics on the countries of the world. http://data.unicef. org/resources/state-worlds-children-2016statistical-tables/

3. Awaliyah $R Q$, Yunitasari E, Nastiti AA. Faktor yang berhubungan dengan pemberian asi eksklusif oleh ibu di ponkesdes pilang kabupaten sidoarjo. Indonesia journal of Community Health Nursing. 2014; 3(1): 57-59. doi: 10.20473/ijchn.v3i1.12210

4. Infodatin. Situasi dan analisis ASI eksklusif. Pusat Data dan Informasi Kementerian Kesehatan RI: 2-4. www.depkes.go.id > download > infodatin > infodatin-asi
5. Valle LMLD, Singh GD, Feliciano N, Machuca MC. Associations between a history of breastfeeding, malocclusion and para functional habits in Puerto Rican children. PR Health Sci J. 2006; 25(1): 31-34.

6. Sum FHKMH, Zhang L, Ling HTB, Yeung CPWY, Li KY, Wong HM, Yang Y. Association of breastfeeding and three-dimensional dental arch relationships in primary dentition. BMC Oral Health. 2015;15:30. doi: 10.1186/s12903-015-0010-1.

7. Bahadure RN, Thosar N, Gaikwad R. Occlusal traits of deciduous dentition of preschool children of indian children. Contemp Clin Dent. 2012; 3(4): 443-447. doi: 10.4103/0976-237X.107437

8. Primasari A, Ria N, Sutadi H, Eyanoer PC. Effect of breastfeeding on the difference of dentocraniofacial growth among children aged 3-5 years old malay and batak ethnic. IOSR 2017; 16(6): 50-53. doi: 10.9790/0853-1606025053

9. Dutra ALT, Berto PM, Vieira LDS, Toledo OA. Longitudinal changes in the molar relationship from primary dentition to permanent dentition. ConScientiae Saude. 2009; 8(2): 171-176. doi: 10.5585/conssaude.v8i2.1640

10. Prado BN, Magalhaes LNC, Ferreira RI, Junior HS. Study of terminal relationship of the second molars in the deciduous dentition. Revista de Odontologia da Universidade Cidade de São Paulo. 2007; 19(1): 6-12.

11. Babu NSV, Moureen AA. Assessment of prolonged breastfeeding and bottle-feedinging on antero-posterior relationship of dental arches in children. International Journal of Current Research. 2017; 9(5): 51307-51311.

12. Romero CC, Scavone JH, Garib DG, Ferreira CRI, Ferreira RI. Breastfeeding and non nutritive sucking patterns related to the prevalence of anterior open bite in primary dentition. J Appl Oral Sci. 2011; 19(2): 161-168.

doi: 10.1590/s1678-77572011000200013

13. Nahás Scocate, Marinho RB, Moura PX, Alves AP. Association between infant feeding 
duration and terminal relationship of primary second molars. Braz J Oral Sci. 2011; 10(2): 140-145. doi: 10.20396/bjos.v10i2.8641659

14. Scavone-Jr H, Guimarães-Jr CH, Ferreira RI, Nahás ACR, Vellini-Ferreira F. Association between breastfeeding duration and nonnutritive sucking habits. Community Dent Health. 2008; 25(3): 161-165.

15. Elad D, Kozlovsky P, Blum O, Laine AF, Po MJ, Botzer E, Dollberg S, Zelicovich M, Ben Sira L. Biomechanics of milk extraction during breastfeeding. Proc Natl Acad Sci USA. 2014; 111(14): 5230-5235.

doi: 10.1073/pnas.1319798111
16. Ria N, Sutadi H, Primasari A, Chairani P. Association between breastfeeding and dentocraniofacial growth and development among 3-5 years old children in two ethnics group of North Sumatera. Journal of Biology, Agriculture and Healthcare. 2016; 6(14): 17-23

17. Chen X, Xia B, Ge L. Effects of breastfeeding duration, bottle-feeding duration and non-nutritive sucking habits on the occlusal characteristic of primary dentition. BMC Pediatric. 2015; 15: 46-52.

doi: 10.1186/s12887-015-0364-1. 